\title{
Economic Benefit Analysis of 220 kV Energy-saving Power Transformer*
}

\author{
Weili Chen ${ }^{1}$, Xian $\mathrm{Ma}^{1}$, Jingtian $\mathrm{Bi}^{1}$, Zhisen $\mathrm{Li}^{2}$, Tong Jiang ${ }^{1}$ \\ ${ }^{1}$ State Key Laboratory of Alternate Electrical Power, System with Renewable Energy Sources, \\ North China Electric Power University, Beijing, China \\ ${ }^{2}$ Tai'an Power Supply Company, Shandong Electric Power Corporation \\ Email: 303696602@qq.com
}

Received January, 2013

\begin{abstract}
Power transformer serves as one of the most widely used electrical equipments in power grid. During the operation, terrible losses are produced. With the development of loss reduction technology of power transformers, in order to save energy saving and reduce emissions, the old power transformer should be replaced. The paper summarizes the main method to reduce the losses of power transformers and brings up the improved Total Owning Cost (TOC) algorithm, which applies to $220 \mathrm{kV}$ power transformers' comprehensive benefit analysis. Using the improved Total Owning Cost (TOC) algorithm, based on today $220 \mathrm{kV}$ energy-saving power transformer manufacturing level, the economic benefits of new energy-saving power transformer and the return period of investment are analyzed. Finally, combined with energy-saving effect, the appropriate replacement proposal of $220 \mathrm{kV}$ power transformers has been given.
\end{abstract}

Keywords: 220 kV Power Transformer; Loss Reduction Technology of Transformer; TOC Algorithm; Economic Analysis

\section{Introduction}

As the transmission and distribution infrastructure, power transformer is widely used and always run a long time. Power transformer on the one hand is high efficiency transmission electrical products, on the other hand is consumption power electrical equipment. Although the efficiency of the transformer can be as high as $99 \%$, but the consumption of electric energy is still very amazing [1]. According to the statistics, the losses of power transformer itself account for more than $3 \%$ of generation [2], therefore carrying out power transformer comprehensive benefit calculation and putting forward reasonable replacement proposal is the important link to reduce the power loss and to achieve the results of energy saving and emission reduction.

\section{Today 220 kV Transformer Manufactur- ing Leve}

According to GB/T 6451-2008, specification and technical requirements for oil-immersed power transformers, the highest rated no-load active loss of $180000 \mathrm{kVA} / 220$ $\mathrm{kV}$ three winding on-load changer transformer is $P_{o}=$ $156 \mathrm{~kW}$, and the highest rated load reactive loss is $P_{k}=$

\footnotetext{
"Supported by the National High Technology Research and Development of China 863 Program (2012AA050208).
}

$630 \mathrm{~kW}[3]$. Now, through inputting new materials and manufacturing technology improvement, the load and no-load losses of $220 \mathrm{kV}$ power transformers have been greatly reduced. The main reduction means mainly consists of the following:

\subsection{Reduce the No-load Loss of Power Transformers}

Now the mainstream of technologies to reducing the no-load loss of transformers are using new type of core material; using best quality core manufacturing process; using high quality insulation structure; reducing the technology coefficient; improving core structure; reduceing the core window size; designing no resonance core; using wound core transformer, etc. [4]The most effective method is using new type of core material and using wound core transformer. Due to the cost, low saturated flux density, easy to produce debris and other reasons, amorphous alloy is not suitable for large power transformer. Similarly, because the today's technology is still unable to meet the requirements of the large size core be winded continuously, wound core currently only suitable for small and medium distribution transformer. For 220 $\mathrm{kV}$ power transformers, high-quality silicon steel sheet is suitable to reduce the unit loss of the core, such as 23ZH90. The relationship between silicon steel sheet and 
power transformer no-load loss is calculated. The results are shown in Table 1. With the reduction of no-load loss, the cost is increasing.

\subsection{Reduce Load Loss of Power Transformers}

The common methods to reduce load losses are using improved core structure to reduce the coil turns; calculating ampere-turns balance of coil to control the radial leakage; using low loss low resistance wire; using advanced insulation structure; choosing appreciate conductor transposition way, etc.[3]Among them, the most fundamental method to reduce load losses is reducing the resistance of conductor, which can be achieved by increasing the cross-sectional area of the wire, namely select the wire in accordance with the requirement of larger capacity transformer.

\subsection{Reduce the Additional Loss of Power Transformers}

The measures to reduce additional loss are using transposition wire and composite wire reasonably to reduce eddy-current loss, stray loss and additional loss; opti- mizing parallel wires' transposition to reduce circulation loss caused by magnetic flux leakage; taking effective shielding measures in the structure.

Table 1. Different silicon steel sheet and no-load active losses Comparison.

\begin{tabular}{lcc}
\hline \multicolumn{1}{c}{$\begin{array}{c}\text { Specifications of silicon } \\
\text { steel sheet }\end{array}$} & $\begin{array}{c}\text { The no-load active } \\
\text { losses(kW) }\end{array}$ & $\begin{array}{c}\text { Drop } \\
\text { rate(\%) }\end{array}$ \\
\hline $\begin{array}{l}\text { 0.3mm Common silicon steel sheet } \\
\text { 30Q150 }\end{array}$ & 204.5 & 0 \\
$\begin{array}{l}\text { 0.3mmHI-B High permeability } \\
\text { silicon steel sheet 30QG130 }\end{array}$ & 177.3 & 13 \\
$\begin{array}{l}\text { 0.3mmHI-B Laser processing high } \\
\text { permeability silicon steel sheet }\end{array}$ & & \\
30RGH120 & 163.6 & 20 \\
$\begin{array}{l}\text { 0.27mm Common silicon steel } \\
\text { sheet 27Q140 }\end{array}$ & & 6.67 \\
$\begin{array}{l}\text { 0.27mmHI-B High permeability } \\
\text { silicon steel sheet 27QG110 }\end{array}$ & 190.9 & 26.7 \\
$\begin{array}{l}\text { 0.23mmHI-B Laser processing } \\
\text { high permeability silicon steel } \\
\text { sheet 23ZH90 }\end{array}$ & 150.0 & 40 \\
\hline
\end{tabular}

Table 2. Transformers’ parameters and prices.

\begin{tabular}{ccccccc}
\hline \multirow{2}{*}{$\mathbf{I d}$} & \multicolumn{6}{c}{ Transformers' parameters and prices } \\
\cline { 2 - 7 } & $\mathbf{P}_{\mathbf{k}}(\mathbf{k W})$ & $\mathbf{P}_{\mathbf{0}}(\mathbf{k W})$ & $\mathbf{I}_{\mathbf{0}} \%$ & $\mathbf{U}_{\mathbf{k}} \%$ & $\mathbf{S}_{\mathbf{n}}(\mathbf{k V A})$ & price(yuan) \\
\hline 1 & 520 & 84 & 0.20 & 14 & 180000 & 6660000 \\
2 & 500 & 86 & 0.20 & 14 & 180000 & 6780000 \\
3 & 480 & 87 & 0.20 & 14 & 180000 & 6720000 \\
4 & 460 & 88 & 0.20 & 14 & 180000 & 6960000 \\
5 & 430 & 94 & 0.20 & 14 & 180000 & 7500000 \\
6 & 400 & 102 & 0.20 & 14 & 180000 & 8190000 \\
\hline
\end{tabular}

Shandong Electric Power Equipment Company have made some research achievements in the loss reduction technology of power transformers, typical SSZ-180000/ 220 products' rated load active loss dropped gradually from $600 \mathrm{~kW}$ to $390 \mathrm{~kW}$, rated no-load reactive loss from $130 \mathrm{~kW}$ to $90 \mathrm{~kW}$, there are some actual products in this interval.

The price of transformers is estimated, setting the typical transformers' rated load active loss to constant value, using the most advanced no-load loss reduction technique, which guarantees the lowest no-load loss. Transformers' parameters and prices are estimated such as Table 2 shows:

\section{Select $220 \mathrm{kV}$ Power Transformer Using Total Owning Cost (TOC) Algorithm}

\subsection{Total Owning Cost (TOC) Algorithm and Its Improving}

The Total Owning Cost (TOC) algorithm is the traditional method to make economic analysis and evaluation of distribution transformer. TOC value $=$ initial investment of distribution transformer + the power losses' cost during the life of distribution transformer. According to the TOC value of different transformers, choose the lowest as the optimal solution [5].

When using The Total Owning Cost (TOC) algorithm to choose $220 \mathrm{kV}$ power transformers, there are some defects, which mainly embodied in the calculation for reactive economic equivalent. Reactive economic equivalent is determined by the position of transformer in power grid. For the distribution transformer, Reactive economic equivalent is generally assigned $\mathrm{k}=0.1$ $\mathrm{kW} / \mathrm{kVAR}$. Because $220 \mathrm{kV}$ power transformers mainly used for transmission line, reactance value far outweigh the resistance value, so the value should be less than 0.1 . Improved TOC algorithm calculate reactive economic equivalent of transmission transformer.

1) Calculation formula of TOC

$$
\mathrm{TOC}=\mathrm{C}+\mathrm{A} \times \mathrm{NL}+\mathrm{B} \times \mathrm{LL}
$$

where, NL is rated no-load losses, $\mathrm{kW}$; LL is rated load losses, $\mathrm{kW}$; A is the capital cost per kilowatt of no-load losses during life of transformer, yuan $/ \mathrm{kW}$; B is the capital cost per kilowatt of load losses during life of transformer, yuan $/ \mathrm{kW}$; $\mathrm{C}$ is the price of transformer;

2) Parameters

$$
\begin{aligned}
& \mathrm{NL}=P_{0}+k Q_{0}=P_{0}+k\left(\frac{I_{0} \% S_{n}}{100}\right) \\
& \mathrm{LL}=P_{k}+k Q_{k}=P_{k}+k\left(\frac{U_{k} \% S_{n}}{100}\right)
\end{aligned}
$$

where, $\mathrm{P}_{0}$ is no-load rated active loss, $\mathrm{kW} ; \mathrm{Q}_{0}$ is rated no-load exciting power, $\mathrm{kVAR} ; \mathrm{P}_{\mathrm{k}}$ is load rated active 
loss, $\mathrm{kW} ; \mathrm{Q}_{\mathrm{k}}$ is rated load exciting power, $\mathrm{k}$ "VAR; $\mathrm{I}_{0} \%$ is no-load current, $\% ; \mathrm{U}_{\mathrm{k}} \%$ is impedance voltage, $\% ; \mathrm{S}_{\mathrm{n}}$ is transformer rated capacity, kVA.

$\mathrm{k}$ is reactive economic equivalent. Reactive economic equivalent means transformers' reactive power consumption increase or decrease per $1 \mathrm{kVAR}$ formed the heat losses increase or decrease $\mathrm{kW}$ value in higher level electricity grid. The Heat losses increase or decrease in value only by Reactive power consumed power itself Current Square caused. Reactive economic equivalent is calculated as follow:

The active losses of higher level electricity grid with no transformer accessed in:

$$
\begin{aligned}
\Delta \mathrm{P}_{0} & =3 \mathrm{I}^{2} \mathrm{R} \times 10^{-3}=\left(\frac{\mathrm{P}}{\mathrm{U}}\right)^{2} \mathrm{R} \times 10^{-3}+\left(\frac{\mathrm{Q}}{\mathrm{U}}\right)^{2} \mathrm{R} \times 10^{-3} \\
& =\Delta \mathrm{P}_{\mathrm{P}}+\Delta \mathrm{P}_{\mathrm{Q}}
\end{aligned}
$$

where, $\Delta \mathrm{P}_{0}$ is the active losses of higher level electricity grid with no transformer accessed, $\mathrm{kW}$; I is system current, A; $\mathrm{U}$ is system voltage, $\mathrm{kV} ; \mathrm{R}$ is line resistance, $\Omega$; $\mathrm{P}$ is system active power, $\mathrm{kW}$; $\mathrm{Q}$ is system reactive power, kVAR; $\Delta \mathrm{P}_{\mathrm{p}}$ is the active power losses caused by Delivery active power, $\mathrm{kW} ; \Delta \mathrm{P}_{\mathrm{Q}}$ is the reactive power losses caused by Delivery reactive power, kVAR..

The active losses of higher level electricity grid when transformer accessed in:

$$
\Delta \mathrm{P}=\left(\frac{\mathrm{P}+\Delta \mathrm{P}_{1}}{\mathrm{U}}\right)^{2} \mathrm{R} \times 10^{-3}+\left(\frac{\mathrm{Q}+\Delta \mathrm{Q}_{1}}{\mathrm{U}}\right)^{2} \mathrm{R} \times 10^{-3}
$$

where, $\Delta \mathrm{P}$ is the active losses of higher level electricity grid when transformer accessed, $\mathrm{kW} ; \Delta \mathrm{Q}_{1}$ is reactive losses of transformer, kVAR; $\Delta \mathrm{P}_{1}$ is active losses of transformer, $\mathrm{kW}$.

The active loss changes of higher level electricity grid when transformer accessed in:

$$
\begin{aligned}
\Delta \mathrm{P}_{\mathrm{b}}=\Delta \mathrm{P}-\Delta \mathrm{P}_{0}= & \frac{\Delta \mathrm{P}_{1}^{2}+\Delta \mathrm{Q}_{1}^{2}+2 \times \mathrm{P} \times \Delta \mathrm{P}_{1}+2 \times \mathrm{Q} \times \Delta \mathrm{Q}_{1}}{\mathrm{U}^{2}} \\
& \times \mathrm{R} \times 10^{-3}
\end{aligned}
$$

where, $\Delta \mathrm{P}_{\mathrm{b}}$ are the active losses changes of higher level electricity grid when transformer accessed in.

So, the reactive economic equivalent is:

$$
\mathrm{k}=\frac{\Delta \mathrm{P}_{\mathrm{b}}}{\Delta \mathrm{Q}_{1}}
$$

Assume that the system power factor $\cos \varphi=0.9$, load rate is $70 \%$. Using per-unit value, estimate the value of reactive economic equivalent. Because $220 \mathrm{kV}$ transmission line resistance value is about $20 \%$ of reactance value, and the reactance value generally take for $0.1 \Omega$, so resistance value is 0.02 . The reactive economic equivalent of $220 \mathrm{kV}$ new energy-saving transformers listed above can be calculated. The values are approximately equal 0.04 .

3) Coefficient A and B

$$
\begin{aligned}
& \mathrm{A}=k_{P W} \times\left(E J L \times 12+E L \times h_{P Y}\right) \\
& \mathrm{B}=k_{P W} \times(E J L \times 12+E L \times \tau) \times P^{2} \\
& k_{P W}=\{1-[(1+a) /(1+i)] n\} /(1-a)
\end{aligned}
$$

where, $k_{p W}$ is present value; EJL is the basic tariff in dual tariff system, yuan $/ \mathrm{kW} \cdot$ month; EL is the Power tariff, yuan/ $\mathrm{kWh} ; h_{p Y}$ is Annual operating hours, generally is $8760 \mathrm{~h} ; \tau$ is annual maximum load loss hours; $P$ is Transformer maximum load factor; $i$ is Annual interest rate; a is inflation rate; $n$ is useful life.

\subsection{The Example of Improved Toc Algorithm}

1) The Total Owning Cost

Using improved TOC algorithm, the economic benefits of $220 \mathrm{kV}$ power transformers listed above can be analyzed.

Assume that the average loss parameters of $220 \mathrm{kV}$ power transformers using in power grid approximated as the loss parameters specified in $\mathrm{GB} / \mathrm{T}$ 6451-2008. $\mathrm{P}_{0}=$ $156 \mathrm{~kW}, \mathrm{P}_{\mathrm{k}}=630 \mathrm{~kW}, \mathrm{I}_{0} \%=0.49, \mathrm{U}_{\mathrm{k}} \%=14.3$. the price is estimated $¥ 6000000$. Other new energy-saving transformers' parameters is shown in Table 2.

Taking the transformer whose $\mathrm{P}_{0}=84 \mathrm{~kW}, \mathrm{P}_{\mathrm{k}}=520$ $\mathrm{kW}$ as an example, assume the load rate of transformer is $70 \%, \mathrm{n}=20, i=7 \%, \mathrm{a}=5 \%, k_{P W}=15.72, \mathrm{EJL}=20, \mathrm{EL}$ $=0.52, h_{p Y}=8760$.

$$
\begin{aligned}
& \mathrm{NL}=P_{0}+k Q_{0}=P_{0}+k\left(\frac{I_{0} \% S_{n}}{100}\right)=98.4 \mathrm{~kW} \\
& \mathrm{LL}=P_{k}+k Q_{k}=P_{k}+k\left(\frac{U_{k} \% S_{n}}{100}\right)=1528 \mathrm{~kW}
\end{aligned}
$$

Assume the maximum load rate is $100 \%$, the annual maximum load loss hours $\tau$ can be calculated, $\tau=4292.4$ h. From the Table 2, can see the price of transformer is $\mathrm{C}$ $=6660000 y u a n$. Thus, coefficient A and B and the total owning cost (TOC) can be calculated.

$$
\begin{gathered}
\mathrm{A}=k_{P W} \times\left(E J L \times 12+E L \times h_{P Y}\right)=75380.54 \\
\mathrm{~B}=k_{P W} \times(E J L \times 12+E L \times \tau) \times P^{2}=38860.59 \\
\mathrm{TOC}=\mathrm{C}+\mathrm{A} \times \mathrm{NL}+\mathrm{B} \times \mathrm{LL}=73456434 \mathrm{yuan}
\end{gathered}
$$

Similarly, the TOC value of different transformers under different load rates can be calculated. As shown in Figure 1.

2) The return period of investment

The old power transformer should be replaced, but selecting different transformer to replace, the return period of investment is also different.

Regardless of the time value of the capital, the return period of investment $=$ the price of transformer/the loss cost price between old and new transformer. 
$=6660000 \div\{[75380.54 \times(192-98.4)+38860.59 \times(1659.6$ $-1528)] \div 15.72\}=8.6$ years

Considering the time value of the capital, plug 8.6 into the formula of $k_{p w}$, Can get the return period of investment in consideration of the time value of the capital:

$$
\begin{aligned}
& \mathrm{n}=\ln [1-(0.07-0.05) \times 8.6] \div \ln [(1+0.05) \div(1+ \\
& 0.07)]=10 \text { yerars }
\end{aligned}
$$

Similarly, the return period of investment of different transformers under different load rates can be calculated. As shown in Figures 2 and 3, here just list the situation of load rate is $70 \%$ and $50 \%$.

Figure 1 shows that The Total Owning Cost of typical energy-saving transformers has greatly reduced compared with old transformers. Although the differences is small between new energy-saving transformers, but the return period of investment and the total energy-saving benefit can vary a lot.

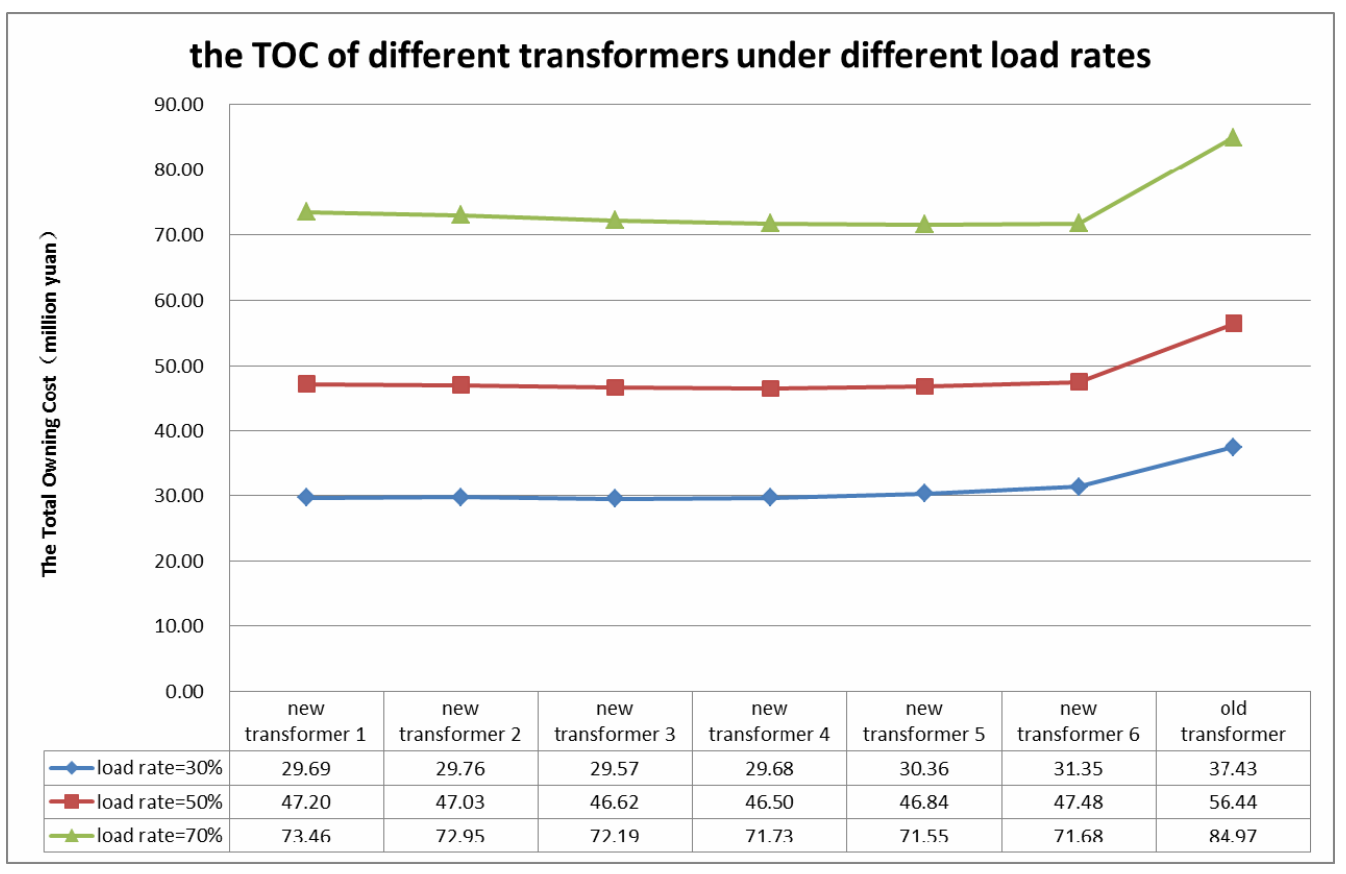

Figure 1. The TOC of different transformers under different load rates.

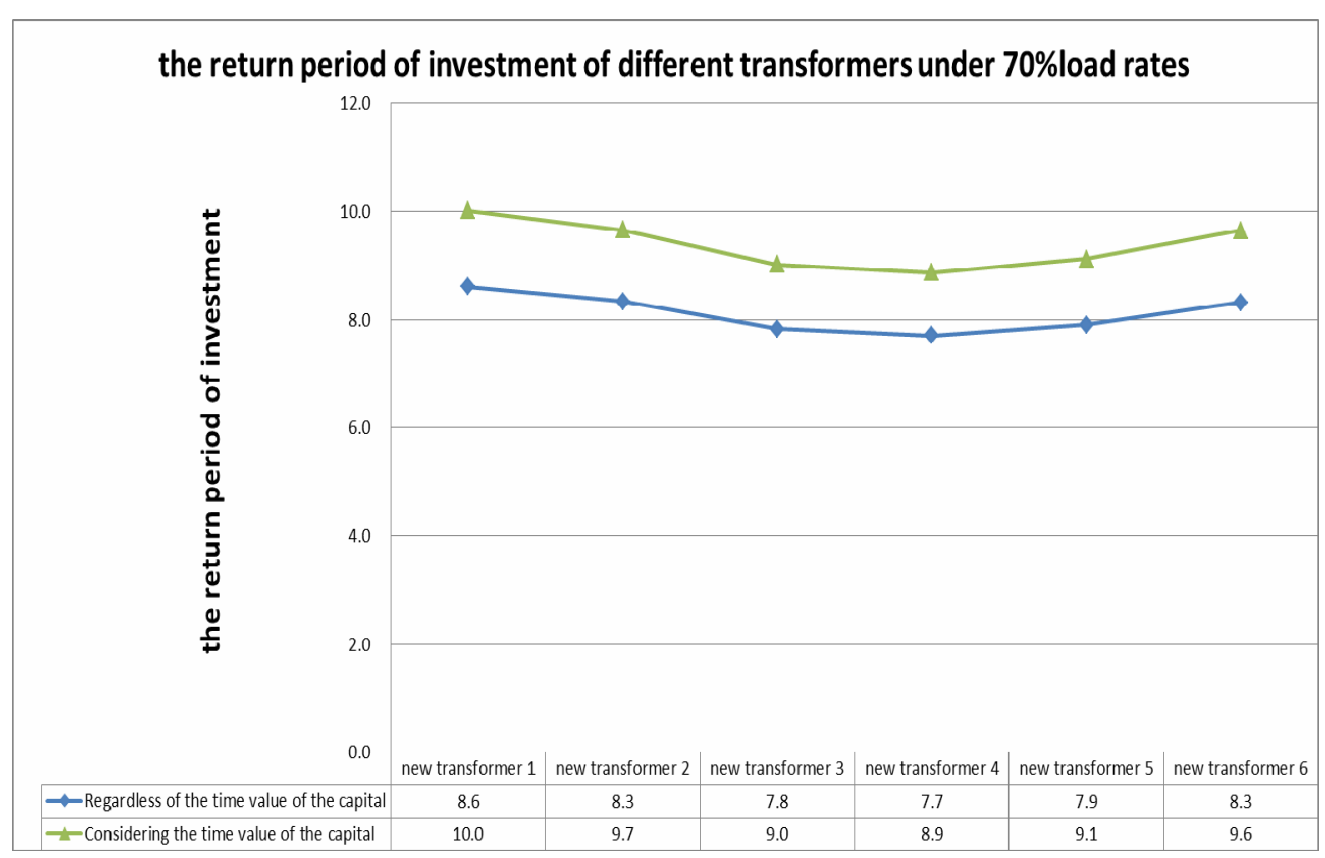

Figure 2. The return period of investment of different transformers under $\mathbf{7 0} \%$ load rates. 


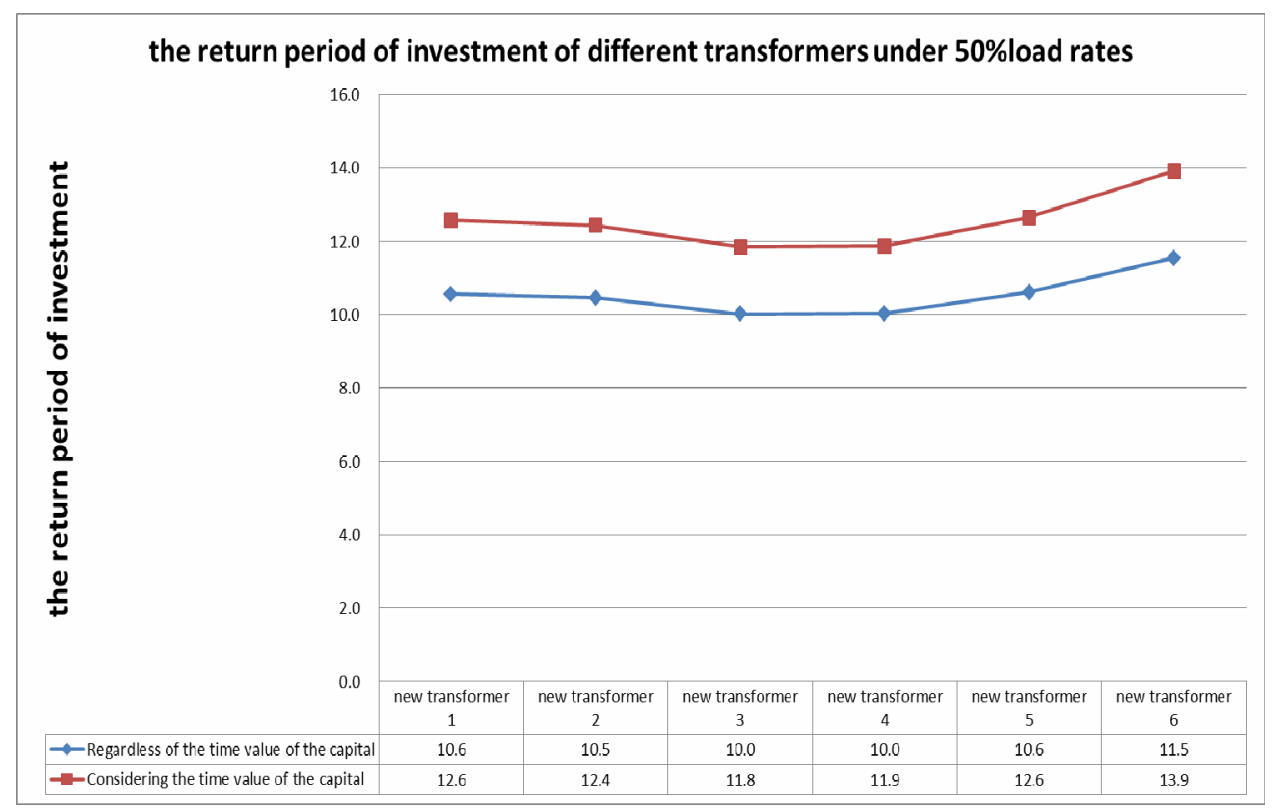

Figure 3. The return period of investment of different transformers under $\mathbf{5 0 \% l o a d ~ r a t e s . ~}$

If the average load rate of local $220 \mathrm{kV}$ transformers is about $70 \%$, choose the transformer which the return period of investment is shortest. According the calculation, new energy-saving transformer 3 and 4 is the most optimal selection. The price of transformer 3 is lower, but the total energy-saving effect of transformer 4 is more obvious. Choose transformer according to need. If choose transformer 4, The Total Owning Cost lowers 13.24 million yuan.

This paper assume that the average loss parameters of $220 \mathrm{kV}$ power transformers using in power grid approximated as the loss parameters specified in GB/T 64512008. But the actual situation may be different. Therefore the replacement proposal in the paper only applies for the transformers whose loss parameters is equal to or higher than the loss parameters specified in GB/T 6451-2008.

\section{Conclusions}

With the development of the energy-saving technology of power transformers, the losses of $220 \mathrm{kV}$ transformers reduce obviously. In order to save energy and reduce emission, it is advised to replace the transformers whose loss parameters is equal to or higher than the loss parameters specified in GB/T 6451-2008 by new energysaving ones. The replacement should base on the Total Owning Cost, the return period of investment, energysaving effect, and the local load rate of transformers. It is illustrated by an example in which the load rate is $70 \%$. The calculation of several typical power transformers is made and the conclusion is drawn. The energy-saving effect is best if the substitution is energy-saving power transformers whose $P_{k}=460 \mathrm{~kW}$ and $P_{0}=88 \mathrm{~kW}$. The initial investment is least if the substitution is energysaving power transformers whose $P_{k}=460 \mathrm{~kW}$ and $P_{0}=$ $87 \mathrm{~kW}$

\section{REFERENCES}

[1] B. C. Ying, "The Energy-saving Ways to Transformer and the Analysis of Its Potential," Energy Conservation, Vol. 4, 1992, pp. 4-7.

[2] K. He, "Transformer Industry Standard Expansion of Energy-saving [N/OL], China Quality News, 2012-11-08 (2) http://www.cqn.com.cn/news/zgzlb/dier/642204.html.

[3] General Administration of Quality Supervision, "Inspection and Quarantine of the People's Republic of China," Specification and Technical Requirements for Oil-immersed Power Transformers GB/T 6451-2008. China ISBN, Beijing: Standards Press of China, 2008.

[4] J. L. Xu, "Method to Reduce Power Transformer Loss," Vol. 3, 2012, pp. 26-35.

[5] Y. B. Gao, "The Research of Economy Capacity of Medium Voltage Distribution Transformer," Shanghai: Shanghai Jiao Tong University, 2010. 